\title{
BEYOND WILENSKEY: A SPECULATIVE MODEl of Professional DeVOlution
}

THEODORE JOHN SWYSTUN ${ }^{1}$

\begin{abstract}
Many writers have explored the processes by which traditional occupations and skilled trades have evolved into the modern professions, as well as the conditions and social accommodations necessary for those transitions to occur (Parsons 1939, Larson 1979, Swick 2000, Cruess et al., 1997, 2000, 2004, etc.). Beginning in the second half of the $20^{\text {th }}$ century, a number of technological, economic, political, and social forces began to collectively undermine the societal terms and conditions under which established professions operate to the extent that it is now possible to speculate that the adaptation mechanisms of several of the professions will prove inadequate for the emerging environment and suggesting that those professions may devolve back into occupations and trades. Harold Wilenskey (1964) examined the development of eighteen professions from the 17th through the 20th centuries and offered a five stage model of professional development. Central to Wilenskey's model is the formation of a "first collective," - in his terminology, a professional association. Using Wilenskey's general model, this paper will suggest that, under certain conditions, a "second collective" may form in response to an external challenge, and that this formation can be a key initiator of devolutionary processes. A complementary speculative model of profession devolution is then proposed. This paper will explore only the processes involved in, and not the social implications of, professional class displacement.
\end{abstract}

KEYWORDS: Sociology of Work, Social Impact of Technology, Wilenskey, Professions, Devolution, Social Change.

\section{INTRODUCTION}

Wilenskey (1964, p. 141 et seq.) describes the process by which occupations and trades have evolved into the modern professions, by tracking their historical development in the United States from 1646 through 1950. He proposes what can be described (greatly simplified) as a five-stage evolutionary process. Other writers, both pre- and post-Wilenskey have approached the construct of a profession from differing perspectives, while largely consistent with key elements of Wilenskey's conceptual framework (Parsons 1939, on the formation of normative authority; Larson 1979, on the transformation of skills and knowledge into forms of

1 Theodore John Swystun (1) https://orcid.org/0000-0003-4443-9675 
privilege; Swick 2000, on control and application of a specialized body of knowledge; Lim et al. 2012, on a human capital approach to professional status development; and the Cruess team at McGill University 1997, 2000, 2004, on various aspects on professions as vocations in service to others.)

Wilenskey's model only addresses the evolution of a profession from the arising of a social need to its maturity, acceptance, and self-regulation; he does not address the complementary process of professional devolution, i.e., the process by which a profession may revert back to an occupation or trade. Although Wilenskey does not explore devolutionary processes, there are indications that such processes were then contemporaneously evident in socialist societies (Kennedy and Sadkowski 1991, Gloeckner 1991, Kraus 1991), although their manifestation then was somewhat different than their current presentation in the West.

\section{THE CONSTRUCT OF A PROFESSION AND WILENSKEY'S MODEL}

Wilenskey proposes a model based on a common pattern of progression beginning (Stage 1) with the arising of a social need and the coalescence around that need of skilled practitioners with technical knowledge and specializations acquired from other occupations.

In Stage 2, training schools are established, either independently or in affiliation with an existing university, from which emerge, standard terms of reference and practice, and a formalization of the knowledge base. He observes (p. 144) that, "This underscores the importance of the cultivation of a knowledge base and the strategic innovation role of universities and the early teachers in linking knowledge to practice and creating a rationale for exclusive jurisdiction."

In Stage 3, professional associations (termed here, the first collectives) are formed, by both early entrants to the field and early recipients of formal training; practitioners viewed as incompetent are culled from the field; sub-specialization begins to first emerge; and conflict with closely related professions, regarding exclusive jurisdiction, begin to develop. The professional associations developed during this stage seek to proactively define the relationship between the professional and the service population and the emergence of what Parsons (1939) termed "normative authority" occurs.

In Stage 4, attempts are made to consolidate the status of the profession - and its exclusive jurisdiction - in law. Whether a legal accommodation is reached or not, it is generally during this stage that a pax inter professionibus ${ }^{2}$ emerges - an informal accommodation between closely related professions tacitly recognizing jurisdictional lines of demarcation.

In Stage 5, with consolidation of the professional body of knowledge, establishment of normative authority with the service population, and the exclusive professional domain established, professional codes of ethics in support of the self-regulation of the profession begins to emerge and the profession becomes established. An overview of Wilenskey's model may be found in Illustration 1.

2 “Peace between the Professions," my term, not Wilenskey's. 


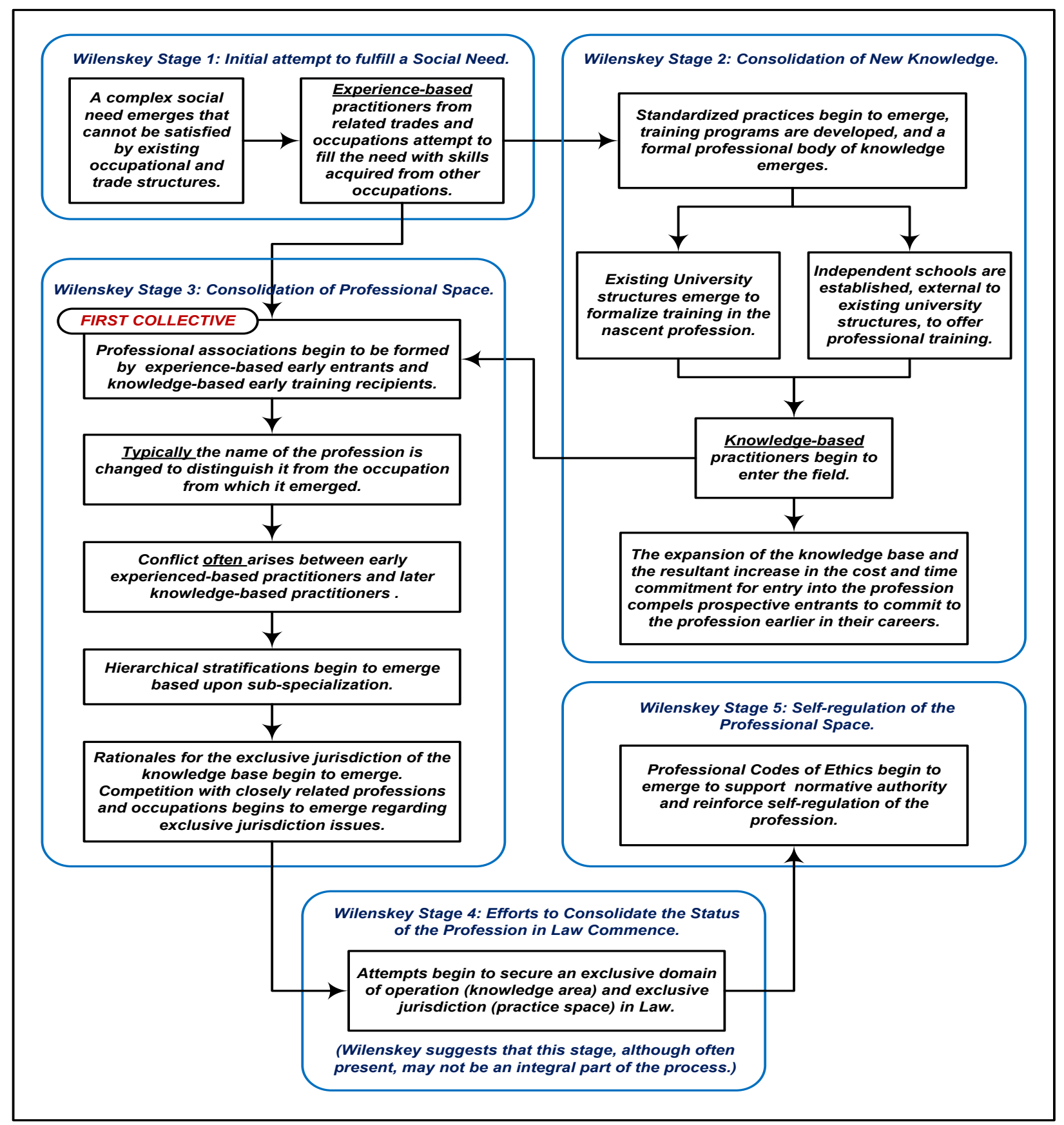

Illustration 1 - Overview of the Wilenskey Model

\section{Challenges to THE CONSTRUCT}

Stein (1960), as modified by Faunce and Clelland (1967), (and re-evaluated here3), identified four fundamental challenges to occupational structures: industrialization, urbanization, bureaucratization, and technological

${ }^{3}$ Stein (1960) identified the first three processes, industrialization, urbanization, and bureaucraticization, with Faunce and Clelland (1967) adding a fourth, professionalization. In the Faunce and Clelland analysis, professionalization is considered to be a "process" that is an "effect" of technological change. This analysis suggests that technological change is itself the process. 
change. While all four were important to the evolution of professionalism, this does not appear to be the case with the emergent phenomenon of devolution, wherein only the latter two have thus far exerted any significant influence. ${ }^{4}$ These challenges manifest as external forces on the profession, threatening to cause a loss of control by the profession, on the very elements that define the profession.

Typically, we are talking about a loss of control of: entry to the profession; professional training and development; fees and compensation; personal accountability and professional self-regulation; and control of the professional knowledge base. These forces often present in combination.

Virtually all attempts to define a profession include reference what Cruess, et al. (2004, p. 74) described as "the mastery of a complex body of knowledge and skills." The growth of that knowledge in the 20th century has been explosive in terms of absolute volume, complexity, and the accelerating rate of its production. Although it may still be the most significant source, the creation of new professional knowledge is no longer solely the provenance of the professions themselves. Knowledge generation is now heavily driven by external factors. Even when generated within the profession, the underlying research is often underwritten by commercial enterprises, e.g., pharmaceutical manufacturers, software companies, medical imaging equipment manufacturers, etc., and that new information can often involve interdisciplinary elements and new and complex technologies. Additionally, for many professions, the growth and expansion of government into formerly unregulated areas has also increased the complexity of professional practice and changed the relationship of the professional practitioner to the service population, e.g., privacy and data protection regulations, errors and omissions liability coverage requirements, etc. While in come contexts these may not be considered core professional knowledge areas, they are essential to the conduct of a professional practice and need to be considered.

It has recently been estimated that it would require 160 hours per week to keep up with the current medical literature in cancer treatment alone and that every five years, medical information doubles in volume (IBM 2013). Clearly, this is a level beyond the ability of a single professional to maintain for any significant period. The absolute volume of new knowledge is not the only issue confronting the professional however; issues related to the relationship of the professional to the new knowledge are also in evidence.

One of the "in-process" professions identified by Wilenskey - Librarians - presents an interesting case in point, demonstrating how a technological agent - the online access through consortia holding collections of digitized content - can exacerbate the decline of normative authority and, with it, professional status.

${ }^{4}$ Hall (1967), examining the internal dynamics of professional-organizational conflict within a proposed schema for the classification of professional firms, uses similar terms - but with different meaning - to illustrate the balance between developed normative systems and highly bureaucratized organizational systems. 
In the US in 1880, less than a decade after the founding of the American Library Association, a dedicated professional association and one of Wilenskey's key milestones of professional formation, (i.e., the first collective), there were 636 librarians nationwide (Beveridge et al. 2011). ${ }^{5}$ The profession grew steadily in numbers up to the Second World War, climbing to just under 50,000. In the post-war era, the number exploded, reaching a high of 307,273 in 1990. From 1990 onward however, the membership of the profession collapsed, sinking to 212,742 in 2009 - a 31\% decline over two decades, representing a loss, in absolute numbers, greater that the total growth over the first 80 years of the profession. Today, according to the US Bureau of Labor Statistics ${ }^{6}$ (BLS 2014), the mean compensation for librarians is $\$ 48,260$, just marginally above the mean national compensation of $\$ 47,230$, and below that of Postal Service clerks at $\$ 49,040$ (a job that does not even require a high school diploma), a serious impediment for future recruitment, even if the demand existed. Further, if we look at the aging of the cohort, we see a portent of future decline. In 1990, only $42 \%$ of librarians were 45 or older; by 2000 , that figure had climbed to $64 \%$, with $40 \%$ of them over 55 . A super-majority of professional librarians active in 2000 have now reached or are approaching retirement age. Although the rate of decline has lessened, the decline, in absolute numbers, continues.

In 2014, the first public library in the US without any physical books opened in San Antonio, Texas (AP 2014). In its first year of operation, it attracted over 100,000 patron-visits. This follows the launching of the Digital Public Library of America in April of 2013, which itself is modeled on the Europeana Library in Europe and the Australian National Library's Trove initiative (Lever 2013) and follows the World Digital Library, introduced in 2007 at UNESCO headquarters in Paris. The Digital Public Library of America (DPLA) alone provides access to more than 34,327,000 million items ${ }^{7}$ and, using the free WUD application developed by the University of Fribourg in Switzerland, ${ }^{8}$ online users can now search - and access - an additional 30 million items ${ }^{9}$ held in the Europeana Library simultaneously. Discussions to provide concurrent

${ }^{5}$ Historical occupational levels in this section are from Beveridge et al. (2007), although compensation levels are from the Bureau of Labor Statistics (BLS 2014), using Occupational Code 00-0000 for All Occupations, 25-4000 for All Librarians, and 43-5051 for Postal Service Clerks. The two sources are not in agreement on compensation levels. Beveridge et al. base their levels on the Integrated Public Use Micro-data Samples (IPUMS) maintained by the Minnesota Population Center. The Bureau of Labor Statistics is an operational unit of the US Department of Labor and a principal agency of the US Federal Statistical System within the US Office of Management and Budget. As such, BLS compensation statistics are considered definitive.

${ }^{6}$ As a point of disclosure, the author provides advisory services to the US Department of Labor. Conclusions and opinions expressed herein are those of the author alone. The statistics cited here are from May 2014, the latest figures publicly available.

7 As of 1 August 2019, https://dp.la/browse-by-partner.

8 https:// scout.wisc.edu/archives/r46830/digital_public_library_of_america_application_wud

9 Digital Public Library of America Strategic Plan: 2015 through 2017, p.7 (https://dpla.wpengine.com/wpcontent/uploads/2018/01/DPLA-StrategicPlan_2015-2017-Jan7.pdf). Item counts for the DPLA and 
WUD access to the collections of the Deutsche Digitale Bibliotek, the British Museum, and Trove are underway. In terms of this analysis, these consortia may be understood as a second collective, in service to a technological agent, which the profession is increasingly focused on supporting. In terms of normative authority, specialized knowledge, exclusivity of domain, control of entry, and societal value (the latter, solely as reflected in compensation), the case can be made that Librarians, as a profession, are clearly on the path to devolution.

Similar, although less advanced, cases may also be found in the examples of Optometry and Pharmacy.

Optometrists, another one of Wilenskey's list of emerging professions are, in the US, a state-licensed and state-regulated profession. ${ }^{10}$ On 27 July 2015, a firm called Opternative launched the world's first online refractive eye examinations in the US, administered via computer and smartphone (Vision Monday 2015a). Registered with the Food and Drug Administration, the tests are now available in 27 states, and have been approved in 45. Although the tests are limited initially certain procedures for certain age groups, at launch, $75 \%$ of the US target population is covered. Results from the computer examination will be reviewed by licensed optometrists; however the mandatory clinical trials of the technology have proved to be highly favorable (Dow 2015) and the cost significantly below the current market cost for an in-office examination. Although, in recognizing the seriousness of the challenge, there has been push-back from the profession (Vision Monday 2015b), ${ }^{11}$ the direction of the change seems clear.

In June 2015, Smart Vision Labs announced the development of a similar smartphone-based device that employs wavefront aberrometry to measure refractive error and in July 2015, Warby Parker, an online eyeglass retailer announced they were investing in similar technology, shortly after raising $\$ 100$ million in the marketplace. Although it is not suggested that these specific technologies alone will devolve the profession of optometry, they will tend to greatly reduce demand and profitability, which taken in concert with future developments may prove decisive. The displacement of normative authority from the professional to a

Europeana Library should be understood to include items other than just printed texts, such as audio and video recordings, photographs, etc.

${ }_{10}$ Within the US, generally speaking, optometrists, examine and prescribe corrective lenses, and are distinct from opticians, who manufacture spectacles, and ophthalmologists, who are qualified medical doctors specializing in the medical and surgical care of the eyes. The overlapping jurisdictions of these fields differ from state to state, with some states giving optometrists the ability to prescribe medications and perform certain minor medical procedures. Clearly, on an international level, these differences will also exist, and may be even more pronounced. The specific definition of "optometry" intended by Wilenskey is uncertain. The OED definition is used here.

${ }^{11}$ It has been suggested that the legal challenges brought by the National Board of Examiners in Optometry against Opternative Co-Founder Steven Lee, OD, regarding a previous business venture were, in essence, an attempt to impede Opternative's launch. 
technology platform (agent), and the relegation of the professional to an employee of a large corporation (the second collective) with no customer/client contact, whose function it is to validate the performance of the technology platform, on a salaried employee basis, is an indicator of professional devolution.

In the case of pharmacists, it should be noted that the vast majority of medications available today are sufficiently complex that they cannot be formulated locally. Virtually all pharmaceuticals arrive at the pharmacy in the form and strength in which they are subsequently dispensed. Even if local formulation were possible, the costs to do so would not be competitive with large scale automated manufacturing, with its high level of process and quality assurance. Yet, it is in the era of local formulation that the professionalization of pharmacists - and their attendant status - emerged.

Technology, in this case, has pushed the practice of professional knowledge from the local pharmacists up the supply chain to the manufacturer and significantly redefined the role of pharmacists as part of the distribution cycle. Already, there are numerous challenges to even that role. With the commoditization of pharmaceuticals, numerous technological agents have emerged to handle distribution, e.g., RxMedic, ${ }^{\text {TM,12 }}$ ScriptPro, ${ }^{\circledR, 13}$ PillPick, ${ }^{\circledR}, 14$ etc. - effectively robot pharmacists.

These agents greatly reduce the risk of cross-contamination, increase the accuracy of dispensing, labeling, control, record keeping, and can instantly warn of adverse interactions between hundreds of medications. Some of these technological agents are capable of processing 225 prescriptions per hour and can dispense 700 different medications. Strong arguments can be made regarding their reliability and efficacy (Fung and Leung 2009). The costs of these technological agents, however, has placed significant stress on the small independent pharmacy, whose volume and profitability may not warrant or permit the initial investment, leading to the cycle of consolidation and mergers in evidence today (Klein 2012, Ford 2014). These mega-pharmacies, of which pharmacists are increasingly becoming employees, many be understood as a second collective, and, as with the previous examples, they effectively relegate the professional to the status of a salaried employee servicing a technological agent, and remove the key element of normative authority from the professional-client relationship.

\section{MECHANISMS OF ADAPTATION}

To adapt to these challenges, a number of response mechanisms have evolved. In Illustration 2, three typical response mechanisms to a knowledge base expansion challenge are illustrated.

\footnotetext{
12 http://www.rxmedic.com/pharmacy-robots/automated-dispensing-system.html

${ }^{13} \mathrm{http}: /$ www.scriptpro.com/products/robot-dispensing/package-dispensing-robots/SPUD/

14 http://www.swisslog.com/en/products/HCS/medication-management-systems/PillPick-automatedpackaging -and-dispensing-system
} 
These are amongst the most common responses and, in particular, the technological agent response is currently in evidence in the professional decline librarians, as previously discussed, pharmacists (Ford 2014), optometrists (Pai 2015, Vision Monday 2015a), and to a lesser extent, lawyers (Davis 2010, Brooks 2011, State Bar of Wisconsin 2011, ILTA 2014) and accountants (Montagna 1968), although, in these latter cases, there are other significant elements involved.

While response mechanism will vary widely based upon specific circumstances, they can generally be classified into four patterns:

- Absorption / Relational Transference - Absorption is the internalization of new knowledge or technology into an existing profession/sub-specialty. This is the standard mechanism of professional growth and is the process by which new knowledge, skills, and techniques are incorporated into a profession. Relational Transference, on the other hand, is an extreme case of incorporation in which the work of the professional is also transformed from a provider of services to the service population to the support of a technological agent that now provides the services directly. Relational Transference need not be absolute and can present in degrees. It is often associated with the formation of consortia, collaboratories, and similar large-scale approaches to the provision of professional services to the service population.

- Expression ${ }^{15}$ - The formation of new sub-specialties within the existing profession. This response mechanism is typical of the medical field and, in many circumstances, but not all, can be tied to the introduction of new technologies and the growth of specialized knowledge.

- Abscission ${ }^{16}$ - This mechanism references the narrowing redefinition of core skills in order to address the expansion of the knowledge base. Peripheral functions, previously considered core professional activities, are transferred to subordinates or related specialties, or out-sourced to service agencies. This can often lead to adopting a different form of business structure.

- Fragmentation is the splitting of an existing profession into two distinct professions. The classic example of which is the fragmentation of IT. In the early 1960s, data processing, as it was then known, was often considered an element of accounting, its primary purpose. As the technology developed and new applications and capabilities emerged, IT became a completely new professional field, independent of accounting. This is a special form of displacement wherein a peripheral activity, formerly confined to supporting a core professional activity, becomes professionalized itself, owing to knowledge expansion (absorption), subsequently manifesting as a new profession.

\footnotetext{
15 Using the definition of expression as "something that manifests something else," from the Latin expressus, to press out under pressure.

${ }^{16}$ In this sense, borrowed from the biological definition of shedding a body part to evade a predator; the body part being a function performed by the professional and the predator being the challenge.
} 


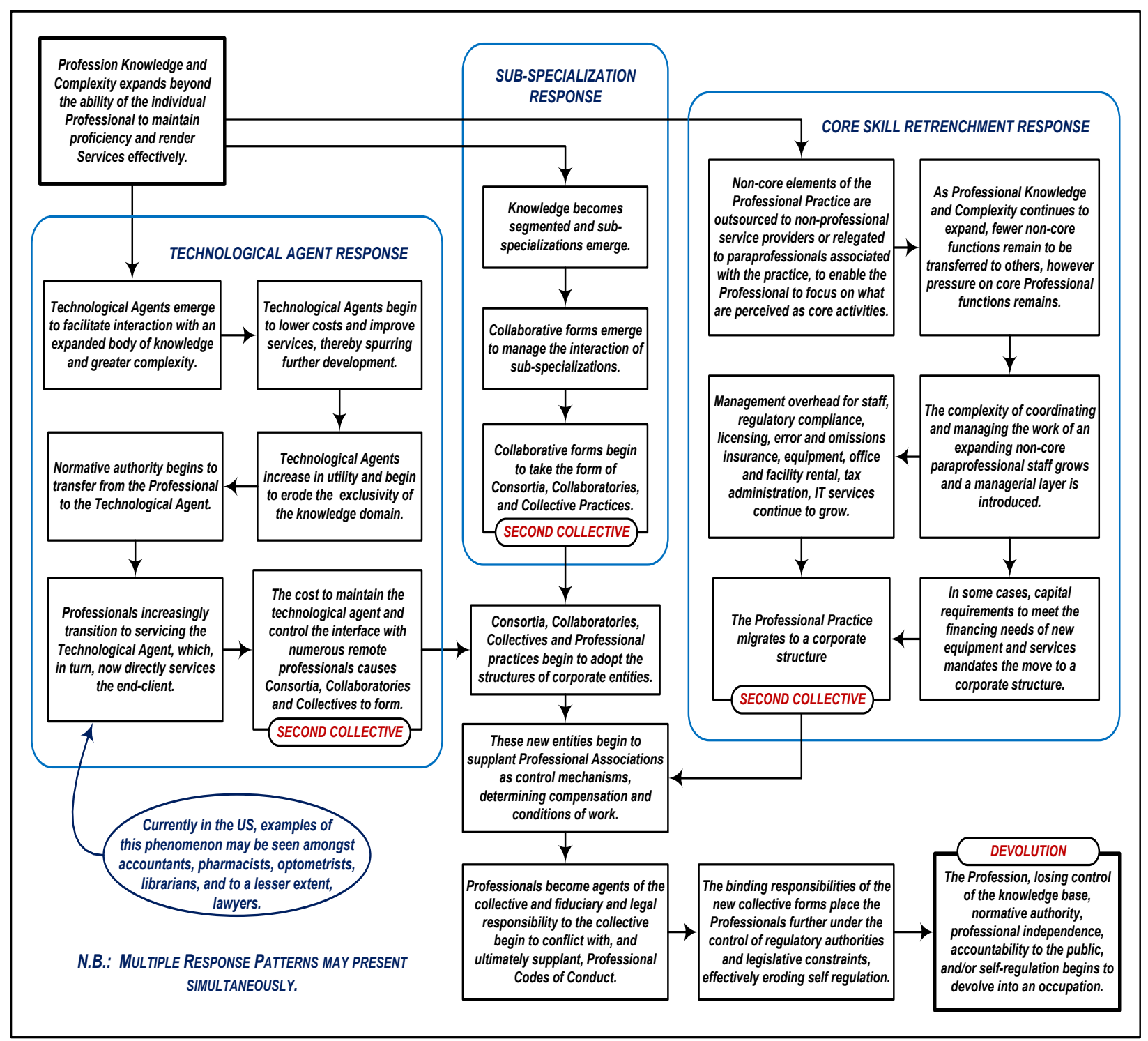

Illustration 2 - Typical Response Mechanisms to Professional

Knowledge and Complexity Expansion

\section{THE EMERGENCE OF THE SECOND COLLECTIVE AND ITS SIGNIFICANCE TO DEVOLUTION}

Despite the differences between the mechanisms, a common (and key) element may manifest in the formation of a second collective. It is suggested here that the formation of the second collective is a necessary precursor in the devolution of a profession. This second collective, which may be a collaboratory, consortium, corporation, labor union, etc., addresses the immediate challenge, however in doing so, it fundamentally changes the mechanism of interaction between the profession and the service population. Wherein the first collective is proactively focused on the nexus between the profession and the service population, the second collective is reactively formed as a response to external challenges, such as knowledge base expansion, the legislative/regulatory environment, financial stress, etc. It is typically the operation of the second collective 
and not the initial challenge that has the greatest impact on the devolutionary trajectory, since it undermines the terms and conditions under which a profession operates. The organizational forms of the second collective are the organizational forms of occupations and trades. While some have argued that under certain conditions, professions and professionals can continue to function within the forms more clearly associated with occupations functioning in a corporate environment (Corwin 1961, and in particular, Hall 1967, p. 463, commenting on "professional employees subordinated to an administrative framework") it is not clear that this can be sustained indefinitely, and may simply be a regulator of devolutionary speed.

Illustration 3 shows a simplified version of Wilenskey's Model of Professional Evolution and the Speculative Model of Professional Devolution, proposed here.

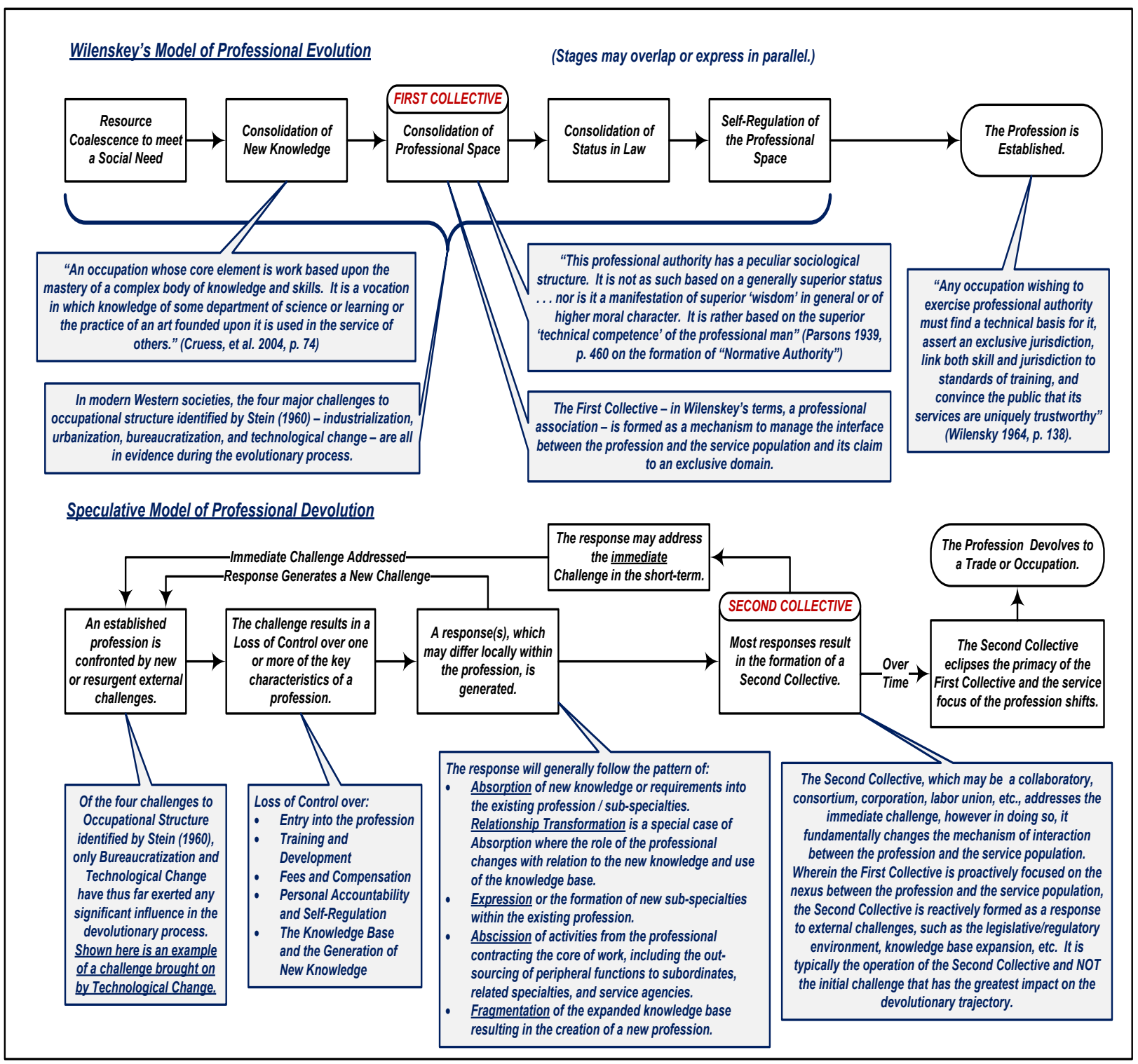

Illustration 3 - The Full Cycle: A Comparison of Wilenskey's Model of Professional Evolution and the Speculative Model of Professional Devolution 


\section{CONCLUSIONS}

The social context of professions, with its reliance on the development of normative authority and the acceptance of exclusive jurisdiction, makes the established professions particularly vulnerable to the rapid rise of technological agents capable of controlling vast professional knowledge bases and providing many professional services, more rapidly, accurately, reliably, conveniently, and economically, than is possible via a human agent. Further, the erosion, limitation, and constraints on independence imposed by rapidly changing market conditions and an ever-expanding regulatory and legislative environment have generally caused professions to lose control of entry to the professional fields; the development and control of new knowledge; fees and compensation; and personal accountability and self-regulation.

To address these challenges, professions have adopted a spectrum of response mechanisms. In many instances, these mechanisms promote the formation of, what has been termed here, "second collectives," in order to facilitate the nexus between: the professional and the service population; the professional and expanding knowledge requirements; sub-specialties within a profession; and the control of abscised professional skills, now relegated to non-professionals.

Over time, the very form of these secondary collectives tends to erode the construct of professions by placing intermediary bureaucratic structures between the professional and the service population, and redirecting the professional's legal and service obligations to parties and agents other than the service population.

\section{REFERENCES}

AP (2014) San Antonio library offers glimpse of bookless future. Re-published online at Phys.org. 3 January 2014. http://phys.org/news/2014-01-texas-library-glimpse-bookless-future.html

Beveridge, Sydney, Susan Weber and Andrew A. Beveridge (2011) Librarians in the U.S. from 1880-2009. OUPBlog, published online by Oxford University Press. blog.oup.com/2011/06/librarian-census, accessed 16 June 2015.

BLS (2014) Occupational Employment Statistics: May 2014 National Occupational Employment and Wage Estimates. Online database at: http://www.bls.gov

Brooks, Robert A. (2011) Cheaper by the Hour: Temporary Lawyers and the Deprofessionalization of the Law. Philadelphia: Temple University Press.

Corwin, Ronald G. (1961) The Professional Employee: A Study of Conflict in Nursing Roles, American Journal of Sociology, 66(2):604-615

Cruess, Sylvia R. and Richard L. Cruess (1997) Professionalism Must Be Taught. British Medical Journal, 315(7123):1674-1677.

Cruess, Richard L., Sylvia R. Cruess, and Sharon E. Johnston (2000) Professionalism: an ideal to be sustained. Lancet, 356 (9224): 156-159. 
Cruess, Sylvia R., Sharon Johnston, and Richard L. Cruess (2004) "Profession": A Working Definition for Medical Educators. Teaching and Learning in Medicine, 16(1):74-76.

Davis, Tread (2010) "Changes and Challenges in Law Practice in the Past Fifty Years," CSA Bulletin, Summer 2010: 27-32.

Dow, C. Thomas (2015) Clinical Trial Summary Report. Chicago: Opternative. Available at: hhtp://www.opternative.com/clinical study, 17 August 2015.

Faunce, William A. and Donald A. Clelland (1967) Professional and Stratification Patterns in an Industrial Community, American Journal of Sociology, 72(1): 341-350.

Ford, George (2014) More independently owned drugstores closing in Iowa, nation: Competition from chains, changes in Medicare making times hard. The Gazette, 24 March 2014. Available at: http://thegazette.com/2013/01/02/more-independently-owned-drugstores-closing-in-iowa-nation

Fung, Esther Y. and Belling Leung (2009) Do Automated Dispensing Machines Improve Patient Safety? Canadian Journal of Hospital Pharmacy, 62(6):516-517

Gloeckner, Eduard (1991) "Soviet Engineers as a Professional Group" in Anthony Jones, ed. Professions and the State: Expertise and Autonomy in the Soviet Union and Eastern Europe. Philadelphia: Temple University Press, 91-118.

Hall, Richard H. (1967) Some Organizational Considerations in the Professional-Organizational Relationship, Administrative Science Quarterly, 12(4):461-478.

IBM (2013) Memorial Sloan Kettering Cancer Center: IBM Watson helps fight cancer with evidence-based diagnosis and treatment suggestions. Press release. Somers, NY: IBM

ILTA (2014) Legal Technology Future Horizons: Strategic Imperatives for the Law Firm of the Future. Austin, TX: International Legal Technology Association.

Kennedy, Michael D. and Konrad Sadkowski (1991) “Constraints on Professional Power in Soviet-Type Society: Insights from the 1980-1981 Solidarity Period in Poland" in Anthony Jones, ed. Professions and the State: Expertise and Autonomy in the Soviet Union and Eastern Europe. Philadelphia: Temple University Press, 167-195.

Klein, Karen E. (2012) End of Days for Independent Pharmacies? Bloomberg Businessweek, 8 March 2012. Available at: http://www.bloomberg.com/bw/articles/2012-03-08/end-of-days-for-independentpharmacies

Krause, Eliott (1991) "Professions and the State in Eastern Europe and the Soviet Union: Theoretical Issues" in Anthony Jones, ed. Professions and the State: Expertise and Autonomy in the Soviet Union and Eastern Europe. Philadelphia: Temple University Press, 3-42.

Larson, Magali Sarfatti (1979) The Rise of Professionalism: A Sociological Analysis. Berkeley: University of California Press.

Lever, Rob (2013) US digital library brings culture, history online. Phys.org blog of 14 April 2013. Available at: http://phys.org/news/2013-04-digital-library-culture-history-online.html\#nRlv 
Lim, Zoe, C. Anderson, and S. McGrath (2012) Professional skills development in a resource-poor setting: the case of pharmacy in Malawi. International Journal of Educational Development, 32(2012): 654-664.

Meltzer, Tom (2014) Robot doctors, online lawyers and automated architects: the future of the professions? The Guardian, Sunday, 15 June 2014.

Montagna, Paua D. (1968) Professionalization and Bureaucratization in Large Professional Organizations. American Journal of Sociology, 74(2):138-145.

Pai, Aditi (2015) Opternative launches online refractive eye exam. Mobihealthnews, 28 July 2015. Available at: http://mobihealthnews.com/45645/opternative-launches-online-refractive-eye-exam/

Parsons, Talcott (1939) The Professions and Social Structure. Social Forces, 17(4):457-467. [Originally delivered as an address before the Annual Meeting of the American Sociological Society in December 1938 and sometimes cited as such.]

State Bar of Wisconsin (2011) The New Normal: The Challenges Facing the Legal Profession. Wisconsin: Board of Governors, State Bar of Wisconsin.

Stein, Maurice (1960) The Eclipse of Community. Princeton, NJ: Princeton University Press. Quoted by Faunce, William A. and Donald A. Clelland (1967) Professionalization and Stratification Patterns in an Industrial Community, American Journal of Sociology, 70(4):341-50.

Swick, Herbert M. (2000) Toward a Normative Definition of Medical Professionalism. Academic Medicine, 75(6):612-616.

Vision Monday (2015a) Opternative Launches World's First Online Refractive Eye Exam Service in 27 States. Vision Monday Magazine (digital edition), 29 July 2015. Available at: http://www.visionmonday.com/latest-news/article/opternative-launches-worlds-first-onlinerefractive-eye-exam-service-in-27-states-1/

Vision Monday (2015b) Opternative Co-Founder Steven Lee, OD, Settles Lawsuit with National Board of Examiners in Optometry. Vision Monday Magazine (digital edition), 17 August 2015. Available at: http://www.visionmonday.com/latest-news/article/opternative-cofounder-steven-lee-od-settleslawsuit-with-national-board-of-examiners-in-optometry-1/

Wilenskey, H.L. (1964) The Professionalization of Everybody? American Journal of Sociology, 70(2):137-158. 